\title{
Knowledge, Attitude, and Perception of Community Pharmacists on COVID-19 Vaccine
}

\author{
Ahmed M Ashour \\ Department of Pharmacology and Toxicology, College of Pharmacy, Umm AlQura University, Saudi Arabia
}

Received October 21, 2021; Revised December 31, 2021; Accepted January 17, 2022

\section{Cite This Paper in the following Citation Styles}

(a): [1] Ahmed M Ashour, "Knowledge, Attitude, and Perception of Community Pharmacists on COVID-19 Vaccine," Universal Journal of Public Health, Vol. 10, No. 1, pp. 62 - 69, 2022. DOI: 10.13189/ujph.2022.100107.

(b): Ahmed M Ashour (2022). Knowledge, Attitude, and Perception of Community Pharmacists on COVID-19 Vaccine. Universal Journal of Public Health, 10(1), 62 - 69. DOI: 10.13189/ujph.2022.100107.

Copyright $\mathrm{C} 2022$ by authors, all rights reserved. Authors agree that this article remains permanently open access under the terms of the Creative Commons Attribution License 4.0 International License

\begin{abstract}
Background: In the past few years, knowledge of COVID-19, its management, patients' care, and its learning curve have been challenging for the professionals in charge of managing the pandemic. Since community pharmacists were the important health care providers who remained the first point of contact during the pandemic, they played a pivotal role in providing counselling services, care, support, and infection control to the public. COVID-19 vaccine remained an important public health measure in curbing COVID-19. Despite its effectiveness in preventing the spread of the disease, a large proportion of the population is unwilling to be vaccinated owing to the lack of adequate knowledge regarding its effectiveness. Purpose: The present study aimed to investigate the perception, attitude, and knowledge of community pharmacists regarding the COVID-19 vaccine. Methods: A cross-sectional survey was conducted using questionnaires to collect data from the community pharmacists in Saudi Arabia. The questionnaire is comprised of four sections: socio-demographic, knowledge, attitude, and practices. Results: Most of the respondents were young adults between the ages of 23 and 34 years $(73.0 \%)$. The study had more male participants $(89.4 \%)$ than female participants (10.6\%). Most of the male respondents were non-Saudi nationals $(77.9 \%)$. The overall percentage of positive responses to the perception questions was $29.9 \%$. The overall percentage of positive responses to the attitude questions was $21.2 \%$. The overall percentage of positive responses to the knowledge questions was $57.4 \%$. No significant difference is recorded between the respondents' intention on taking the vaccine and the age groups $\left(\chi^{2}(9)=\right.$ 7.134, $\mathrm{p}>0.05=0.623)$. However, the remaining
\end{abstract}

characteristics of the test showed significant differences. Conclusion: The findings confirmed that the level of knowledge regarding the COVID-19 vaccine amongst the community pharmacists was high enough to offer reliable advice to patients. However, less than $50 \%$ of the participants had adequate knowledge of the vaccine.

Keywords COVID-19, Pharmacists, Vaccine, Knowledge, Perception

\section{Introduction}

Over the past year, the knowledge and attitude towards management of COVID-19 and patients' care have been challenging for healthcare professionals owing to social distancing and other preventive measures put in place during the pandemic [1]. However, the launching of COVID-19 vaccines makes most activities return to normal. At present, vaccines have been rolled out by several authorized international bodies. While these vaccines have been certified as safe and effective by most regulatory bodies and are currently being distributed globally to curb the widespread of COVID-19 [2], several challenges are remarked regarding evaluating the efficacy of the vaccines. In the wave of the pandemic, other variants of the virus have been emerged, which cause a lot of concerns to health care professionals [3].

With the outbreak of the COVID -19 pandemic, the healthcare system of different countries enacted an effective plan to cope with the disease. Pharmacists remain an important part of these healthcare systems and play a vital role in the management of pandemics $[3,4,5]$. In most 
countries, the current lockdown status made many pharmaceutical stores remain close, and only a few pharmacies especially community pharmacists remained open to offer public service. The community pharmacists were the important health care providers and remained the first point of contact to satisfy the community health needs during the pandemic [6].

The first case of COVID-19 was reported in Saudi Arabia on March 2, 2020 [7]. Several countries especially the Saudi community were flooded with a wave of unreliable information from different sources, especially from social media [8]. Thus, the low level of knowledge could be a block in preventing the spread of COVID-19. The greater the knowledge, the more in diffusing reliable information to prevent the spread of the virus.

Vaccines remained important public health measures in curbing COVID-19. Despite the effectiveness of COVID-19 vaccines in preventing the spread of the disease, a large proportion of the population are unwilling to be vaccinated [9]. Lack of adequate knowledge regarding the efficacy of the vaccine contributed to the unwillingness of the population to take the vaccine. Pharmacists play a vital role in providing reliable information, offering counseling services, care, support, and infection control during the pandemic. The effective role of pharmacists in limiting the spread of the COVID-19 has been emphasized by the (International Pharmaceutical Federation, 2020). As the primary contact with the local population, community pharmacists remain the most reliable source of information for concerned individuals needing advice regarding any ailment [10]. Community pharmacists facilitated information flow about the virus and its vaccines. In different countries, community pharmacists play a central role in controlling and preventing COVID-19. Thus, policymakers must provide better support for this healthcare professional system to improve patient care.

Understanding the level of knowledge and attitude regarding the COVID-19 vaccine among community pharmacists could help in containing the pandemic. The experiences gained from the initial SARS (severe acute respiratory syndrome) outbreak in 2002 revealed that knowledge and attitude towards contagious infections could contain the panic of the general public [11]. This panic also affects the chances of the healthcare system to inhibit infection transmission and a virus outbreak.

The present study aimed to explore the knowledge, perception, and attitude of pharmacists about the COVID-19 vaccine in Saudia Arabia. The findings of this study will assist in providing valid information regarding the COVID-19 vaccine and developing the corrective measures in curbing the spread of the COVID-19.

\section{Materials and Methods}

\subsection{Design}

A cross-sectional survey was conducted by offering questionnaires to community pharmacists across Saudi Arabia. Data were collected during the peak of the COVID-19 pandemic between January 2021 and May 2021. Since no immediate data was available regarding the total number of community pharmacists working in the country during the pandemic, no sampling frame was produced, and a convenience sampling model was used to select the participants. Community licensed pharmacies were enrolled on the survey by sending questionnaires to them online at their respective locations. The selected participants were only the community pharmacies in Saudi Arabia.

The questionnaire comprised of four sections: the socio-demographic section, the knowledge, attitude, and practices section. The questionnaire was critically appraised by independent experts to determine face validity. Additionally, an analysis of the internal consistency of each section was conducted by employing a pilot study of 50 samples. An acceptance criterion was set for a Cronbach alpha score of 0.6 , in which all questions meeting this criterion were included in the final version of the document.

\subsection{Statistical Approach}

The data collected from the questionnaires were analyzed using the statistical package for social studies (SPSS version 20.0), and the completeness and accuracy of the data collected from participants were checked. The demographic characteristics of the respondents were generated using the software's descriptive statistic command. Frequency and percentage were used in the characterization of the knowledge, attitude, and practices of the participants concerning COVID-19.

\section{Ethics}

Ethical approval was obtained from the ethical committee at Umm AlQura University, Saudi Arabia. All guidelines outlined in the Declaration of Helsinki were adhered to by the research group. Dissemination of the questionnaire was conducted via an online platform owing to strict lockdown protocol. The online questionnaire was prepared with a pre-face that outlined the nature and purpose of the study. In addition, the pre-face included a consent section that guaranteed anonymity and voluntary participation of the respondents.

\section{Results}

\subsection{Socio-Demographic Analysis}

A total of 1670 community pharmacists were involved in the survey. Of these, 345 were not fully completed, producing a non-response rate of $24.4 \%$. Most of the respondents were young adults between 23 and 34 years 
(73.0\%) of age, with very few participants nearing their retirement age, 55 to 60 years $(0.6 \%)$. The study had more male participants $(89.4 \%)$ than female participants (10.6\%). Most of the male respondents were Saudi nationals (77.9\%). Most of the respondents resided in a city, from the western region $(42.2 \%)$. However, few respondents were from the eastern region (8.1\%). Most of the respondents reported had a Bachelor's degree (83.6\%) and worked as pharmacists $(70.8 \%)$ with very few reported to be under a fellowship or residency program $(0.2 \%)$ and be technicians $(0.8 \%)$. Most of the respondents $(36.9 \%)$ have between 6 and 10 years of experience in their current field (Table 1).

Table 1. Socio-demographic analysis of 1670 community pharmacists in Saudi Arabia

\begin{tabular}{|c|c|c|}
\hline Variable & Category & Percent \\
\hline \multirow{4}{*}{ Age } & $23-34$ years & 73.0 \\
\hline & $35-44$ years & 23.0 \\
\hline & $45-54$ years & 3.3 \\
\hline & $55-60$ years & 0.6 \\
\hline \multirow{2}{*}{ Gender } & Male & 89.4 \\
\hline & Female & 10.6 \\
\hline \multirow{2}{*}{ Nationality } & Non-Saudi & 77.9 \\
\hline & Saudi & 22.1 \\
\hline \multirow{4}{*}{ Marital status } & Divorced & 0.9 \\
\hline & Married & 74.4 \\
\hline & Single & 24.3 \\
\hline & Widowed & 0.4 \\
\hline \multirow{2}{*}{ Residence } & In a city & 91.7 \\
\hline & In a village & 8.3 \\
\hline \multirow{5}{*}{ Region } & Central & 20.3 \\
\hline & Eastern & 8.1 \\
\hline & Northern & 11.5 \\
\hline & Southern & 17.9 \\
\hline & Western & 42.2 \\
\hline \multirow{6}{*}{ Education } & Bachelor & 83.6 \\
\hline & Diploma & 1.1 \\
\hline & Fellowship or residency program & 0.2 \\
\hline & Master & 1.8 \\
\hline & Pham D & 12.8 \\
\hline & $\mathrm{PhD}$ & 0.5 \\
\hline \multirow{4}{*}{ Job } & Consultant pharmacist & 3.0 \\
\hline & Pharmacist & 70.8 \\
\hline & Senior pharmacist & 25.4 \\
\hline & Technician & 0.8 \\
\hline \multirow{4}{*}{ Years in service } & $<2$ years & 15.7 \\
\hline & $2-5$ years & 19.0 \\
\hline & $6-10$ years & 36.9 \\
\hline & $>10$ years & 28.4 \\
\hline
\end{tabular}




\subsection{Perception toward COVID-19 Vaccine}

The perception of community pharmacists (Table 2) showed that most of them believe that the COVID-19 vaccine failed to have negative adverse effects on the general public (PPR $=17.7 \%)$. A total of $23.6 \%$ of the community pharmacists in Saudi Arabia believed that the pharmaceutical companies were not interested in selling the COVID-19 vaccine. Regarding the perception of community workers to the health care system, $48.3 \%$ of the respondents believed that the system was reliable in managing the COVID-19 vaccine. The overall percentage of positive responses to the perception questions was $29.9 \%$.

\subsection{Attitude towards the COVID-19 Vaccine}

A total of $5.2 \%$ of the respondents hold the attitude that the COVID-19 vaccine is ineffective (Table 2). However, $37.2 \%$ of the sample population hold the attitude that the COVID-19 vaccine is yet to be tested sufficiently on humans. The overall percentage of positive responses to the attitude questions was $21.2 \%$.

\subsection{Knowledge of COVID-19 Vaccine}

The results of the knowledge of the community pharmacists show that most of the pharmacists were more familiar with the different groups not allowed to receive the vaccine (PPR $=63.7 \%$ ). A total of $63.2 \%$ of the respondents reported having knowledge of all types of COVID-19 vaccines. Regarding the negative effects of the vaccine, $62.5 \%$ of the respondents indicated having knowledge of these effects. The community pharmacists had the least knowledge about the steps taken to enhance the safety of the COVID-19 vaccine (47.2\%). The overall percentage of positive responses to the knowledge questions was $57.4 \%$ (Table 4 ).

\subsection{Qualitative Analysis}

The results show that the sampled community pharmacists are most influenced by the decision of the technicians $(22 \%)$ to take the vaccine doses (Table 5). Other pharmacists were the second group of professionals who influenced the community pharmacists' decisions in taking the vaccine doses $(20.2 \%)$. Senior pharmacists (3.3\%) and consultant pharmacists $(2.3 \%)$ have a very low level of influence on the decision of community pharmacists to take the vaccine.

Table 2. The Perception of COVID - 19 vaccine

\begin{tabular}{|c|c|c|c|c|c|c|}
\hline Statement & SDA & DA & $\mathrm{N}$ & A & SA & PPR \\
\hline Coronavirus (COVID-19) vaccine has negative adverse effects? & 0 & 23.9 & 58.3 & 14.3 & 3.4 & 17.7 \\
\hline $\begin{array}{l}\text { Pharmaceutical companies are only interested in sales of coronavirus (Covid-19) } \\
\text { vaccines? }\end{array}$ & 0 & 20.7 & 55.7 & 17.6 & 6.0 & 23.6 \\
\hline $\begin{array}{l}\text { The health care system is not reliable concerning taking the Coronavirus (Covid-19) } \\
\text { vaccine? }\end{array}$ & 19.3 & 10.0 & 41.7 & 38.1 & 10.2 & 48.3 \\
\hline
\end{tabular}

Table 3. Attitude towards COVID-19 vaccine

\begin{tabular}{|c|c|c|c|c|c|c|}
\hline Statement & SDA & DA & N & A & SA & PPR \\
\hline Coronavirus (COVID-19) vaccine is ineffective. & 18.0 & 32.3 & 44.5 & 3.6 & 1.6 & 5.2 \\
\hline \multicolumn{1}{|c|}{ Coronavirus vaccine (Covid-19) has not been sufficiently tested on humans } & 0 & 17.1 & 45.6 & 25.5 & 11.7 & 37.2 \\
\hline $\begin{array}{l}\text { Abbreviations: SDA, strongly disagree; DA, disagree; N, neutral; A, agree; SA, strongly agree; SD, standard deviation; PPR, per cent } \\
\text { positive response }\end{array}$ \\
\hline
\end{tabular}

Table 4. Knowledge about COVID-19 vaccine among community pharmacists in Saudi Arabia

\begin{tabular}{|c|c|c|c|c|c|c|}
\hline Statement & SDA & DA & $\mathbf{N}$ & A & SA & PPR \\
\hline I know the group of people who are not allowed to receive the COVID-19 vaccine. & 0 & 5.7 & 30.6 & 43.8 & 19.9 & 63.7 \\
\hline I know the possible negative effects of the COVID-19 vaccine. & 0 & 6.1 & 31.4 & 44.9 & 17.6 & 62.5 \\
\hline I know the steps taken to test the effectiveness of the COVID-19 vaccine. & 0 & 10.0 & 41.7 & 38.1 & 10.2 & 48.3 \\
\hline I know the steps taken to test the safety of the COVID-19 vaccine. & 0 & 10.4 & 44.5 & 38.0 & 9.2 & 47.2 \\
\hline I know the opinion of scientists in the health field about the COVID-19 vaccine. & 0 & 4.5 & 39.0 & 46.6 & 9.9 & 56.5 \\
\hline I know the opinion of reliable health organizations about the COVID-19 vaccine. & 0 & 3.2 & 36.5 & 48.8 & 11.5 & 60.3 \\
\hline I know all the different types of COVID-19 vaccine. & 0 & 4.5 & 32.3 & 46.7 & 16.5 & 63.2 \\
\hline
\end{tabular}

Abbreviations: SDA, strongly disagree; DA, disagree; N, neutral; A, agree; SA, strongly agree; SD, standard deviation; PPR, per cent positive response 
Table 5. Groups of individuals who influence the community pharmacists' decision to take the vaccine

\begin{tabular}{|c|c|c|}
\hline Technician & Frequency & $\begin{array}{c}\text { Valid } \\
\text { Percent }\end{array}$ \\
\hline Pharmacist & 368 & 22 \\
\hline $\begin{array}{c}\text { Pharmacist, Senior pharmacist, } \\
\text { Consultant pharmacist }\end{array}$ & 337 & 20.2 \\
\hline Technician, Pharmacist & 92 & 14.6 \\
\hline $\begin{array}{c}\text { Senior pharmacist, Consultant } \\
\text { pharmacist }\end{array}$ & 71 & 4.5 \\
\hline Senior pharmacist & 55 & 3.3 \\
\hline Pharmacist, Senior pharmacist & 53 & 3.2 \\
\hline Consultant pharmacist & 39 & 2.3 \\
\hline $\begin{array}{c}\text { Technician, Pharmacist, Senior } \\
\text { pharmacist, Consultant pharmacist }\end{array}$ & 30 & 1.8 \\
\hline Pharmacist, Consultant pharmacist & 14 & 0.8 \\
\hline $\begin{array}{c}\text { Technician, Pharmacist, Senior } \\
\text { pharmacist }\end{array}$ & 6 & 0.4 \\
\hline Technician, Consultant pharmacist & 3 & 0.2 \\
\hline Technician, Senior pharmacist & 4 & 0.2 \\
\hline
\end{tabular}

A total of $5.6 \%$ of the respondent claimed that non-supportive policies were to blame for the low uptake of the vaccine (Table 6). However, $3.7 \%$ of the participants reported that patients were unwilling to use pharmacy services as the main deterrent from vaccine uptake in their areas.

Some respondents $(15 \%)$ indicated they trusted none of the sources regarding the COVID-19 vaccine (Table 7). Other sources were the most trusted source of information regarding the COVID-19 vaccine (14.9\%). A total of $10 \%$ of the respondents trusted the Internet more than social media to source reliable information regarding the vaccine. Other media outlets such as newspapers, magazines, radio, television, and social media only gained the trust of $1.1 \%$ of the respondents as a reliable source of information for the vaccine.

A total of $33.4 \%$ of the respondents indicated they preferred to source their information from two groups: the Ministry of Health and the World Health Organization (WHO). However, $13.5 \%$ of the respondents preferred a combination of the Saudi Ministry of Health, the WHO, and doctors to source information about the COVID-19 vaccine (Table 8 ). A total of $11.9 \%$ of the sample pharmacists preferred the Ministry of Health as their primary source of information for the COVID-19 vaccine. On the other hand, only $2.3 \%$ of the sample preferred to obtain information on the COVID-19 vaccine from other sources.

Table 6. Reasons for low uptake of the COVID-19 vaccine

\begin{tabular}{|c|c|c|}
\hline & Frequency & Valid Percent \\
\hline Time & 218 & 13.1 \\
\hline Lack of knowledge and skills & 93 & 5.6 \\
\hline Non-supportive policies & 73 & 4.4 \\
\hline Non-supportive policies, Time & 61 & 3.7 \\
\hline Patients' unwillingness to use pharmacy services & 57 & 3.4 \\
\hline Shortages in numbers of community pharmacists, Time & 55 & 3.3 \\
\hline Lack of knowledge and skills, Time & 47 & 2.8 \\
\hline Non-supportive policies, Shortages in numbers of community pharmacists, Time & 37 & 2.2 \\
\hline $\begin{array}{l}\text { Lack of knowledge and skills, Lack of confidence and good training, Non-supportive policies, Patients } \\
\text { do not trust community pharmacists, Patients' unwillingness to use pharmacy services, Shortages in } \\
\text { numbers of community pharmacists, Time }\end{array}$ & 31 & 1.9 \\
\hline Lack of knowledge and skills, Lack of confidence and good training, Time & 32 & 1.9 \\
\hline Patients' unwillingness to use pharmacy services, Time & 32 & 1.9 \\
\hline Shortages in numbers of community pharmacists & 31 & 1.9 \\
\hline Lack of knowledge and skills, Lack of confidence and good training & 28 & 1.7 \\
\hline Lack of knowledge and skills, Non-supportive policies & 23 & 1.4 \\
\hline Lack of knowledge and skills, Non-supportive policies, Time & 24 & 1.4 \\
\hline Lack of confidence and good training & 22 & 1.3 \\
\hline Lack of knowledge and skills, Lack of confidence and good training, Non-supportive policies & 22 & 1.3 \\
\hline Non-supportive policies, Patients' unwillingness to use pharmacy services & 19 & 1.1 \\
\hline $\begin{array}{l}\text { Patients' unwillingness to use pharmacy services, Shortages in numbers of community pharmacists, } \\
\text { Time }\end{array}$ & 18 & 1.1 \\
\hline Lack of confidence and good training, Non-supportive policies & 16 & 1 \\
\hline Non-supportive policies, Patients' unwillingness to use pharmacy services, Time & 17 & 1 \\
\hline Patients do not trust community pharmacists & 16 & 1 \\
\hline
\end{tabular}


Table 7. Trusted sources for information about COVID-19 vaccine

\begin{tabular}{|c|c|c|}
\hline & Frequency & Valid Percent \\
\hline None of the trusted sources & 251 & 15.0 \\
\hline Other sources & 248 & 10.0 \\
\hline Internet (not social media) & 167 & 6.2 \\
\hline Social media & 103 & 4.4 \\
\hline Internet (not social media), Other sources & 74 & 3.2 \\
\hline Newspapers and magazines & 54 & 3.2 \\
\hline Social media, Internet (not social media) & 54 & 2.6 \\
\hline Radio and television & 44 & 2.0 \\
\hline Radio and television, Social media & 34 & 1.8 \\
\hline Newspapers and magazines, radio and television & 30 & 1.6 \\
\hline Newspapers and magazines, Internet (not social media) & 26 & 1.6 \\
\hline Other sources, None of these sources I trust & 27 & 1.4 \\
\hline Social media, Other sources & 24 & 1.3 \\
\hline Newspapers and magazines, Social media & 21 & 1.1 \\
\hline Newspapers and magazines, radio and television, Social media & 18 & 1.1 \\
\hline Radio and television, Internet (not social media) & 18 & \\
\hline
\end{tabular}

Table 8. Preferred sources of information regarding COVID-19 vaccine

\begin{tabular}{|c|c|c|}
\hline & Frequency & Valid Percent \\
\hline Saudi Ministry of Health, World Health Organization & 557 & 33.4 \\
\hline Saudi Ministry of Health, World Health Organization, The doctors & 225 & 13.5 \\
\hline Saudi Ministry of Health & 198 & 11.9 \\
\hline World Health Organization & 79 & 4.7 \\
\hline Ministry of Health, The doctors & 42 & 2.5 \\
\hline Other & 38 & 2.3 \\
\hline The doctors & 25 & 1.5 \\
\hline Ministry of Health, World Health Organization, Other & 19 & 1.1 \\
\hline World Health Organization, The doctors & 19 & 1.1 \\
\hline Ministry of Health, World Health Organization, The doctors, Other & 16 & 1 \\
\hline
\end{tabular}

\subsection{Inferential Statistics}

The chi-square was used to compare the participants' characteristics with their intention to take the emerging COVID-19 vaccine. No significant difference was observed between the respondents' intention to take the vaccine and the age groups $(\chi 2(9)=7.134, p>0.05=$ $0.623)$. For the remaining characteristics, the test showed significant differences. Significant difference was observed between the genders $(\chi 2(3)=36.704, p>0.05=$ $0.001)$, nationality $\left(\chi^{2}(3)=68.836, \mathrm{p}>0.05=0.001\right)$, marital status $(\chi 2(9)=26.672, \mathrm{p}>0.05=0.002)$, residency $\left(\chi^{2}(3)=12.402, \mathrm{p}>0.05=0.006\right)$, region $\left(\chi^{2}(12)=\right.$ $35.528, \mathrm{p}>0.05=0.001)$, education $(\chi 2(15)=57.723, \mathrm{p}>$ $0.05=0.001)$, profession $(\chi 2(9)=37.174, \mathrm{p}>0.05=$ $0.001)$, and years of experience $(\chi 2(9)=28.744, \mathrm{p}>0.05=$ 0.001 ).
Table 9. Comparing the participants' characteristics with their intention to take the emerging COVID-19 vaccine

\begin{tabular}{|c|c|c|c|}
\hline Variable & Chi-square & df & P (2 sided) \\
\hline Age & 7.134 & 9 & 0.623 \\
\hline Gender & 36.704 & 3 & 0.001 \\
\hline Nationality & 68.836 & 3 & 0.001 \\
\hline Marital status & 26.672 & 9 & 0.002 \\
\hline Residency & 12.402 & 3 & 0.006 \\
\hline Region & 35.528 & 12 & 0.001 \\
\hline Education & 57.723 & 15 & 0.001 \\
\hline Profession & 37.174 & 9 & 0.001 \\
\hline $\begin{array}{c}\text { Years of } \\
\text { experience }\end{array}$ & 28.744 & 9 & 0.001 \\
\hline
\end{tabular}




\section{Discussion}

All the respondents acknowledged having knowledge of the COVID-19 virus and vaccine. Most of the respondents did not trust the sources of information in the questionnaire as reliable information regarding the COVID-19 vaccine $(15 \%)$. However, most respondents trusted sources of information regarding the Coronavirus vaccine apart from the sources from newspapers, magazines, radio, television, social media, and internet sources other than social media $(14.9 \%)$. These findings were contrary to that of other studies. Three different studies showed that most health workers relied on government websites, news media, and social media as their main source of information for COVID-19 [12, 13]. Although other studies indicated the Internet and social media serve as an important source of information for health workers regarding COVID-19. However, community pharmacists in Saudi Arabia find these sources to be unreliable, and only trusted government websites and traditional media serve as the accurate sources of information for the virus and its vaccine. Therefore community pharmacists in Saudi Arabia are sceptical and keen on verifying information to relay to the general public.

Community pharmacists interviewed have the knowledge of the primary cause of COVID-19 and the biological system it attacks. Community pharmacists also have deep knowledge about the people not supposed to take the COVID-19 vaccine. Similarly, a higher percentage revealed correct responses to knowledge questions regarding the negative effects of the vaccine, the opinion of different health organizations regarding the vaccine, and the different types of vaccines available to the public. Contrarily, other studies found lower percentages of correct responses to knowledge questions regarding different aspects of COVID-19 on health workers [12]. Differences in the study population are associated with the differences in the results between the studies. While these studies [12] were undertaken in Saudi Arabia, other authors focused on the entire spectrum of healthcare workers. A study by Giao et al. [14] was conducted in the city of Ho Chi Minh. Additionally, the differences may be associated with methodology and the time of data collection. Information regarding the COVID-19 and its vaccine is released weekly if not daily basis. As such, community workers are more likely to have significant differences in knowledge regarding the vaccine. Despite the high percentages of positive responses on knowledge questions, the sampled community pharmacists had less adequate knowledge for the two questions: The question about knowledge on the steps taken to test the effectiveness of the COVID-19 vaccine (48.3\%) and that of the steps taken to test the safety of the COVID-19 vaccine $(47.2 \%)$ were average. The implication was that more than half of the pharmacists were misinformed about the vaccine. All community pharmacists should be well informed about the vaccine to assist them in acting as the primary source of reliable information regarding the COVID-19 vaccine.

\section{Conclusions}

The findings confirmed that the level of knowledge regarding the COVID-19 vaccine amongst the community pharmacists is high enough to provide reliable advice to the patients. However, in some aspects, less than half of the participants had adequate knowledge regarding the vaccine. A very small percentage of the sampled population held the view of the COVID-19, and one-third of the respondents had the view that the vaccine had not been sufficiently tested on human subjects. The community pharmacists' perception of the COVID-19 vaccine is positive on the level of its negative effect on the patients and the intentions of pharmaceutical firms in increasing their profit margin. The respondents' perception of the reliability of the healthcare system in safeguarding the safety of the vaccine was not entirely positive as almost half of the participants did not trust the healthcare system to handle the job effectively.

\section{REFERENCES}

[1] Senguta M., Roy A., Gangual A., Baishya K., Chakrabarti S., I. Mukhopadhyah. "Challenges Encountered by Healthcare Providers in COVID-19 Times: An Exploratory Study." Journal of Health Management, vol. 23, no 2, pp. 339-356, 2021

[2] World Health Orgization (WHO), (202, June 11). "Statement for healthcare professionals: How COVID-19 vaccines are regulated for safety and effectiveness", https://www.who.int/news/item/11-06-2021-statement-forhealthcare-professionals-how-covid-19-vaccines-are-regul ated-for-safety-and-effectiveness (accessed Dec. 30, 2021)

[3] Tesfaye Z., Yismaw M., Negash Z., A. Ayele. "COVID-19-Related Knowledge, Attitude and Practice Among Hospital and Community Pharmacists in Addis Ababa, Ethiopia." Integrated Pharmacy Research and Practice, vol 9, pp. 105 - 112. 2020. doi:10.2147/IPRP.S26 1275

[4] Basheti I., Nassar R., Barakat, M., Alqudah R., Abufarha R., Mukattash T., B. Saini. (2021). "Pharmacists' readiness to deal with the coronavirus pandemic: Assessing awareness and perception of roles." Research in Social and Administrative Pharmacy, vol 17, no 3, pp. 514-522, 2021. doi:https://doi.org/10.1016/j.sapharm.2020.04.020

[5] Muhammad K., Saqlan M., Hamdard A., Naveed M., Umer M., Khan S., ... Z Khan. "Knowledge, attitude, and practices of Community pharmacists about COVID-19: A cross-sectional survey in two provinces of Pakistan." medRxiv. 2020 doi: https://doi.org/10.1101/2020.05.22.20 108290

[6] Almohammed OA., Aldwihi LA., Alragas AM., Almoteer AI., Gopalakrishnan S., NM. Alqahtani. Knowledge, 
Attitude, and Practices Associated With COVID-19 Among Healthcare Workers in Hospitals: A Cross-Sectional Study in Saudi Arabia. Front Public Health. 2021; 9:643053. doi: 10.3389/fpubh.2021.643053

[7] Ministry of Health in Saudi Arabia. MOH reports first case of coronavirus infection. https://www.moh.gov.sa/en/Mini stry/MediaCenter/News/Pages/News-2020-03-02-002.aspx (accessed December 26, 2021).

[8] Zhang M., Zhou M., Tang F., Wang Y., Nie H., Zhang L., G. You "Knowledge, attitude, and practice regarding COVID-19 among healthcare workers in Henan, China." J Hosp Infect. vol. 105, no. 2, pp. 183-187. 2020 [PubMed] [Ref list]

[9] Islam MS., Siddique AB., Akter R. et al. "Knowledge, attitudes and perceptions towards COVID-19 vaccinations: a cross-sectional community survey in Bangladesh." BMC Public Health, vol. 21, no. 1851, 2021. https://doi.org/10.1186/s12889-021-11880-9

[10] International Pharmaceutical Federation (FIP), (2020, March 26). "Covid-19: guidelines for pharmacists and the pharmacy workforce”, https://www.fip.org/files/content/pr
iority-areas/coronavirus/COVID-19-Guidelines-for-pharm acists-and-the-pharmacy-workforce.pdf (accessed Dec. 26, 2021).

[11] Zhong B., Luo,W., Li H., Zhang Q., Liu X., Li W., L. Li. Knowledge, attitudes, and practices towards COVID-19 among Chinese residents during the rapid rise period of the COVID-19 outbreak: a quick online cross-sectional survey. International journal of biological sciences, 1745. 2020.

[12] Bhagavathula A., Aldhaleei W., Rahmani J., Mahabadi M., D. Bandari. "Novel coronavirus (COVID-19) knowledge and perceptions: a survey on healthcare workers." medRxiv, 2020

[13] Nemati M., Ebrahimi B., F.Nemati. "Assessment of Iranian nurses' knowledge and anxiety toward COVID-19 during the current outbreak in Iran. Archives of Clinical Infectious Diseases., 9. 2020.

[14] Giao H., Han N., Van T., Ngan V., Van V., P. Le. "Knowledge and attitude toward COVID-19 among healthcare workers at District 2 hospital, Ho Chi Minh City." Asian Pacific Journal of Tropical Medicine, vol. 13 no. (6), p. 260, 2020. 